\title{
Das große Ganze
}

Liebe Leserin, lieber Leser,

die MTZ steht wie keine andere Zeitschrift für Antriebe, ganz gleich, ob verbrennungsmotorisch oder elektrisch. Mit dieser Ausrichtung plädieren wir aus der Redaktion unentwegt für Technologieoffenheit. Der systemische Ansatz ist bei den Emissionen mindestens ebenso wichtig wie bei der Entwicklung. Welcher Antrieb hat demnach die Nase vorn? Wir glauben: alle. Denn unter der Voraussetzung, dass genügend regenerative Energie zur Verfügung steht, sind alle Antriebe, wenn nicht $\mathrm{CO}_{2}$-frei, dann doch zumindest $\mathrm{CO}_{2}$-neutral darstellbar.

Die massive Subventionierung des batterieelektrischen Antriebs greift jedenfalls zu kurz. Zumindest mittelfristig wird der nötige Aufbau von Infrastruktur und Fahrzeugflotte die Vorteile der lokalen Emissionsfreiheit deutlich überlagern und den $\mathrm{CO}_{2}$-Ausstoß sogar erhöhen. Kurzfristig scheint der einzige Weg, die $\mathrm{CO}_{2}$-Ziele zu erreichen, die Einschränkung der Mobilität zu sein, wie sie während der Corona-Krise stattgefunden hat - mit den bekannten Auswirkungen auf die Wirtschaft und unser Sozialleben. Müssen wir uns tatsächlich zwischen der individuellen Freiheit der Mobilität und dem Umweltschutz entscheiden? Oder bieten alternative Lösungswege eine effektive Möglichkeit, die Emissionen zu reduzieren, ohne die Bewegungsfreiheit einzuschränken?

Wichtig ist es, bei allen Lösungsversuchen den Gedanken des noch verfügbaren $\mathrm{CO}_{2}$-Budgets nicht aus den Augen zu verlieren, also die Menge fossiles $\mathrm{CO}_{2}$, die ausgestoßen werden darf, um das Ziel einer maximalen Erderwärmung von $1,5^{\circ} \mathrm{C}$ nicht zu verfehlen. Nach dem Weltklimarat sind das noch 420 bis 580 Milliarden Tonnen.

$\mathrm{Zu}$ bedenken ist, dass auch für eine Versorgung mit Wasserstoff, zumindest auf der letzten Meile, eine neue Infrastruktur notwendig ist. Zudem sind alle damit verbundenen Technologien enorm teuer und im Sinne des $\mathrm{CO}_{2}$-Budgets kritisch zu bewerten. Für synthetische Kraftstoffe können vorhandene Infrastrukturen - angefangen von Tankschiffen und Raffinerien bis hin zur Versorgung über Tankstellen und sogar die existierende Flotte - weiterverwendet werden. Die Kraftstoffproduktion ist aber ungleich energieintensiver als der direkte Einsatz elektrischer Energie.

Wie kann also ein ökologisch und ökonomisch sinnvoller Technologiewandel im Verkehr mit möglichst wenig Einschränkungen für Bevölkerung und Industrie vollzogen werden? Letzten Endes müssen Maßnahmen immer auch daran gemessen werden, ob sie im Einklang mit der Freiheit des Einzelnen zu realisieren sind. Ein Verbot von individueller Mobilität ist dabei ebenso unverhältnismäßig wie eine einseitige Förderung.

Viel Vergnügen beim Lesen dieser Ausgabe der MTZ.

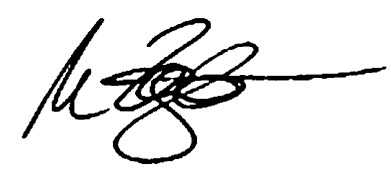

Marc Ziegler

Stellvertretender Chefredakteur

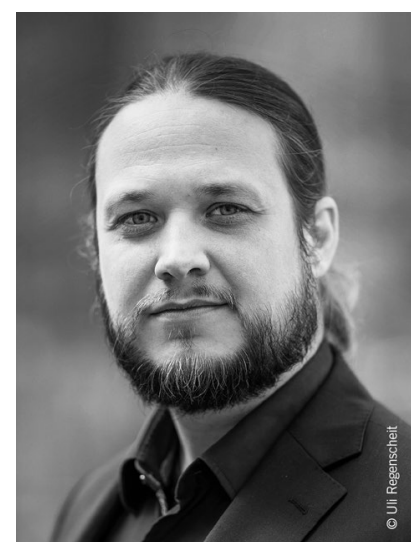

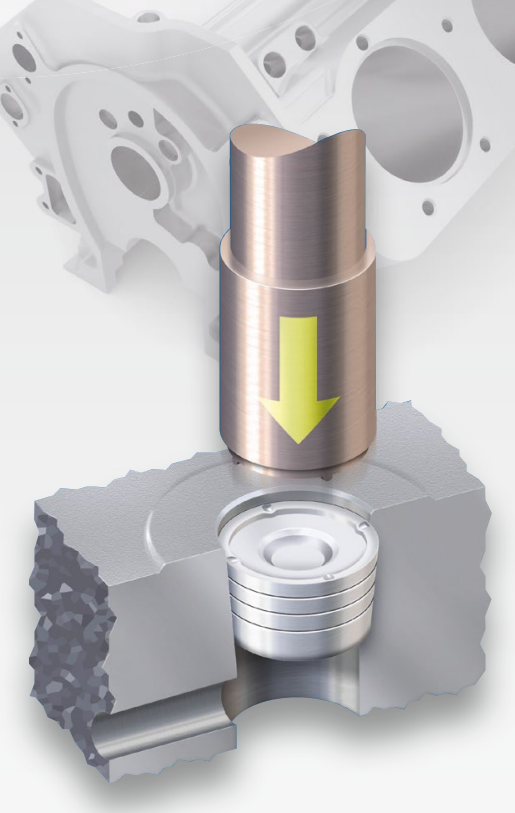

LEE BETAPLUG ${ }^{\circledR}$ Dichtstopfen: Unser bewährtes Konzept, Kanäle und Bohrungen zu verschließen

Das rationelle Prinzip: konischer Verschluss-Stopfen in konischer Aufnahmebohrung.

Im Getriebe- und

Motorenbau, bei Ölfiltern,

Ölkühlern

und -pumpen

sowie anderen Anbauaggregaten.

$\varnothing 5$ bis $20 \mathrm{~mm}$, für Drücke bis 50 bar

Mit BETAPLUG ${ }^{\circledR}$ entsteht ein perfekter formschlüssiger Sitz DICHT UND SICHER!

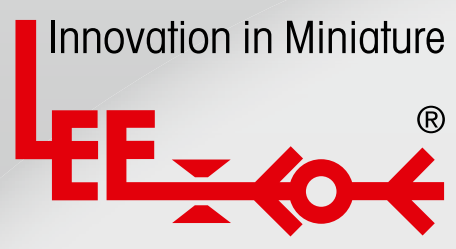

LEE Hydraulische

Miniaturkomponenten $\mathrm{GmbH}$ Am Limespark 2 · D-65843 Sulzbach Németország

(c) $+49(0) 6196 / 77369-0$ info@lee.de www.lee.de 